Medicine Updates Faculty of medicine

October 2021,volume 7, issue 7 https://muj.journals.ekb.egdean@med.psu.edu.eg vice_dean_postgraduate@med.psu.edu.eg DOI: 10.21608/muj.2021.95480.1063

\title{
" Infection control standards and its benefits on operative theater safety management "
}

\section{Authors}

Hoda Ali Hegazy'; Heba Elsayed2; 'Dina Saad

ALghobashi'; Nesma Hassan Eltanahy33; Amr Ahmed Ghazal4; Aya

Ahmed Leil2; Rowida Ahmed Yousef'; Enas Mohamed

Elsalamony5; Hanan Elkhedr AboElhoda6; Aya Seif

Elshahat7; Shimaa Aldeep ${ }^{8}$

${ }^{1}$ Faculty of pharmacy, Mansoura University

${ }^{2}$ Port Said University

${ }^{3}$ Faculty of Pharmacy, 6th of October

University ${ }^{4}$ Faculty of Dentistry, Alexandria

University

${ }^{5}$ Faculty of Pharmacy, Masr University for science and technology

${ }^{6}$ Faculty of Pharmacy, El-Azhr University

${ }^{7}$ Faculty of Dentistry, Delta University

${ }^{8}$ Faculty of Pharmacy, Saini University

Abstract:

Working in the operating room (OR) is a very demanding job, it need very skillful persons working in harmony to give the patient undergoing surgery the care he deserves. The OR staff should react to any abrupt situation very fast and pay attention to each detail to carry out surgical operations safely. One of the big challenges that face the OR team is how to manage or even inhibit infection to 
make sure that the patient and the OR team members are safe. Risk of exposure to blood-borne pathogens or toxic chemicals is a worrying matter among peoples working in healthcare establishments.

Working in the operating room (OR) is a very demanding job, it need very skillful persons working in harmony to give the patient undergoing a surgery the care he deserves. The OR staff should react to any abrupt situation very fast and pay attention to each detail to carry out surgical operations safely. to avoid infection connected with Healthcare (HCAIs)that result in greater morbidity or even mortality, increased hospitalization time and treatment costs in both resource-poor and developed countries (WHO, 2009)

There are factors that may increase the chance of spreading nosocomial infection in the peri-operative period as Anesthetist issues, Patient issues \& Environment issues.

Operating Room Protocol includes Hand hygiene, which is the easiest way to inhibit the spread of infections effectively, and wearing personal barriers (as mask, gloves, Head covers, scrub suits and cover gowns) which are useful where the chances of spreading infections are increased.

Various methods of getting rid of contamination of surgical instruments include: cleaning (either manual or mechanical), purification of the water used, ultrasonic removal of derbies, disinfection (either chemical or thermal) \& sterilization(preferably by autoclaving).

Bagging of instruments is important to minimize the risk of being contaminated after the end of its sterilization.

Prevention of SSIs by well approved measures (e.g., blood glucose stabilization, maintain normal body temperature, inhalation of oxygen) may decrease disabilities and death associated with SSIs and also decrease healthcare expenses. 
Recommendations include the formation of infection control committee consists of a clinical infection control resident and a number of assisting nurses, Create, apply and follow up an annual strategy to ensure medical safety measures, Continuous learning plans for medical staff, Keep the least number of people in the OR during a procedure, Keep doors closed or a minimum entry to minimize air currents and during pandemics especial care should be taken to insure the safety of medical staff and the patient.

\section{Key words:-}

HCAIs - infection - Control- OR- standards -Safety - sterilization.

\section{Introduction: -}

The need to manage infections in health care facilities arises from the need to avoid Healthcare-associated infections (HCAIs) not only for the patients put also for the medical staff members and visitors. HCAI may be described as an infection that occurred in a person during the treatment process in a hospital or other health care establishment that was not present or incubated at the beginning of his treatment. This leads to greater morbidity and mortality, longer hospitalization time and higher treatment costs especially in both resource-poor and developed countries (WHO, 2009). The frequency of hospitalized patients in the developing world was estimated to be $15 \%$, it is also as high as $37 \%$ for patients assigned to the intensive care unit (WHO, 2009 and Iliyasu et al., 2016).

To decrease the incidence of (HCAIs), every patient should be equipped with uniform infection prevention and control strategies (Gammon et. al, 2008). Nevertheless, compliance with any of these measures has been shown to be very low especially in operational environment, including needle stick exposure, hand hygiene, and handling of gloves (Shobowale et.al. 2017).

Even globalized organizations focused on these measures. For example, the WHO has stated that more than $80 \%$ of needle stick exposures can be 
avoided by using security tools and programs (Brady et al., 2008). The causes for this weak compliance were examined, and the main factors affecting information were, in addition to their workload, the level of education, expertise and attitude of the health care team (Zafar et al., 2009).

Surgical site infections (SSIs) are a common risk of surgical procedures and one of the most common types of inpatient infection (Lo Giudice $\boldsymbol{e t}$ al., 2019). Health care professionals are exposed to micro- organisms all the time. Many of these organisms can cause major or even fatal infections (Twitchell, 2003 \&Fashafsheh et al., 2015). Among health care providers especially nurses are often subjected to multiple infections (Kosgeroglu $\boldsymbol{e t}$ al., 2004\& Fashafsheh et al., 2015).

Although there is an increased awareness of nosocomial infections, or hospital acquired infections (HAIs) and attempts to control its occurrence, their percentage is still increasing. In 2011, approximately 722000 persons caught a hospital acquired infection; $9.6 \%$ of them died as a result of this infection. (HAIs, 2014). It has been supposed that in every 100 patients being treated in American hospitals, between 4 to 10 of them will catch a nosocomial infection, especially after surgical interventions or entering IC. unit (HAIs, 2014\& Biddle 2009).

\section{Aim of the work: -}

The study aimed to increase the awareness of infection control measures in operating room in order to achieve better and safer health services.

\section{Methodology:-}

- Operation rooms: The dimensions of the ideal operation theater are $6.5 \mathrm{~m}$ $\times 6.5 \mathrm{~m} \times 3.5 \mathrm{~m}$ or more if a bigger space is needed.

- Doors and Windows: The entry and exit doors should be separate. The width of the door should be approximately 1.2 to $1.5 \mathrm{~m}$. It is better to 
use sliding doors in order to decrease the air currents during the opening and closing of the doors as low as possible. Also foot paddle is recommended in order to open the door without hand usage.

- Glass windows are better than wood, also one sided mirrors can be used.

- The floors: The floors should be non slippery, strong, \& made of large sheets of material to minimize the number of joints to prevent the accumulation of dust and other tiny particles within it.

- Walls: Easy cleaned and light coloured painted walls is recommended.

(https://www.ncbi.nlm.nih.gov/pmc/articles/PMC7882240/).

- The surgical ward consists of two areas: semi- restricted and restricted, the activities done in each area determines its type. The semi-restricted area includes all the supportive areas of the surgical ward, as sterile supplies storage, sterile processing rooms, scrub rooms, and the passages leading to restricted areas. Only the OR team and the patient are allowed to enter this area and they should wear surgical attire and headgear. The restricted area is meant to be completely free of any possible source of infection. In this area, which includes the ORs and clean core, full surgical condoms are obligatory.(National guide to infection control).

- According to the American standards of OR, no particles larger than 0.5 $\mathrm{mm}$ is to be seen when no people are in the room. To make this possible, ORs should have air purification and pressure systems to ensure that air current flow from ORs to the surrounds not the opposite.(National guide to infection control).

- The air in the operating room must be changed at least 20 times every hour, 4 changes of these replace all the air in the room with new one. If financially possible, high-efficiency air filter (HEPA) is recommended. 
The standard temperature of ORs ranges from $68^{\circ} \mathrm{F}\left(20^{\circ} \mathrm{C}\right)$ to $75^{\circ} \mathrm{F}\left(24^{\circ}\right.$ C), and humidity of $20 \%$ to $60 \%$ is acceptable.(National guide to infection control).

- The inanimate theater surroundings should not be a source of SSIs. The cleaning and getting rid of infections in the operating theater should follow a strict routine: for example, floors should be cleaned every day, and at the end of each session. Horizontal surfaces and all surgical tools (e.g., tables, buckets) should be cleaned between surgical interventions. The spillage of any biological fluid should be cleaned at once. Walls and ceilings are seldom heavily contaminated; so cleaning them two times a year is acceptable.(National guide to infection control).

\section{Preparation of the operation room and staff:-}

- All the working personnel in the operating room should perform arm and hand scrubbing using antiseptic solution, for 3-5 minutes before their first procedure of the day, and the time of scrubbing the hands and arms can be less than this time for later procedures. scrubbing underneath fingernails is carried out only once with the first scrub each day. By comparing hand cleansers, no evidence was found that certain type is better than the others in reducing SSIs. The researchers found that chlorhexidine gluconate is slightly better than povidone-iodine in reducing colony-forming units (CFUs), yet more expensive. Also, a three-minute scrub is preferred to a two-minute scrub in reducing (CFUs). The use of an alcoholic antiseptic solution is more effective than the aqueous solution especially when a long surgical procedure is carried out. (National guide to infection control).

- All the working personnel should not wear any kind of jewelry, artificial nails or paint there nails with nail polish as these may hold infectious microorganisms underneath.

- Pathogen-free gloves should be of good quality. Wearing double gloves is recommended in certain surgeries, where the gloves are likely to be 
punctured. For example in orthopedic surgery, gloves are accidentally punctured in half of the cases. Wearing double gloves may also help protect the surgical team of catching viral infections. Gloves should be changed at once after any accidental puncture.

- The operative room should be cleaned thoroughly with a detergent and an antimicrobial soap. Alcohol solutions are more preferable than aqueous solutions to disinfect the patient's skin but it is important to proceed on a completely dry skin. The best reduction in colony-forming units at the surgical site has been reached by using chlorhexidine-alcohol when compared with povidone-iodine in a sterile surgical procedure. No study has clearly stated that the direction of scrubbing the skin from the operative site to the outside is better than other directions. (National guide to infection control).

- The patient and any tool included in the operating room should be covered by pathogen-free drapes which should not be moved after it has been put in it's position. Sticky, plastic-made drapes became popular in the last few years, as it was believed to prohibit the infection of the surgical wound by the skin and subcutaneous tissues but there is no firm evidence on this theory(a review by Webster and al). Many types of drapes are used in operations, disposable or reusable, woven or non-woven drapes but all of them must be sterile of course. (National guide to infection control).

- In very precise operative interventions the surgeon should reduce the risk of SSIs by eliminating dead tissues, good haemostasis where possible, they should hold tissues carefully, use electrocautery only when it is necessary and remove all dead tissue before suturing the cut. Good surgical intervention may be reflected in shorter durations of surgery which is clearly associated with a lower risk of SSIs.

- Dirty cases are carried out at the end of the day, is a good practice that should be followed and then the room is closed and cleaned. 
- Antibiotic-coated cut are believed to decrease SSIs rates theoretically but there is no hard evidence on this.

Although the application of various modalities for the prevention of SSIs have been proposed, such as preoperative and postoperative supplemental oxygen administration, prophylactic use of intranasal ointments like mupirocin, and close monitoring of blood glucose level before the procedure, only 3 specific intervention are proven to effectively help to decrease the incidence of nosocomial infections:

- Pay close attention to hand sanitation.

- Keeping the patient's normal body temperature.

- Administration of antibiotics prior to the surgery with successive doses as shown in (table 1).

\section{Operating Room Protocol}

\section{Hand Sanitation:}

- Hand sanitation done by operation theater staff is the most productive way to inhibit the spread of infections.

- Surgical hand wash:

- Surgical hand wash should be carried out before the operation in order to get rid of the normal flora of the hand.

- Steps:

- Wrists and hands must be free of any jewelry.

- Slightly warm water is to be used to wash the hands and arms to $5 \mathrm{~cm}$ above the elbows to eliminate any attached mud. 
- Before the first sterilization of the hands of the day, a nail cleanser is used to carefully clean underneath and around the nails.

- The nails should be short and not painted with nail polish.

- Antiseptic solution is to be scrubbed on the hands in circles starting from the finger tips of one hand till $5 \mathrm{~cm}$ above the elbow level, do not forget to wash between the fingers. The same steps is to be done for the other limb.

- The rubbing should not be done for less than 3 minuet period and not more than 5 min.

- One side of the disinfected towel is used to dry one arm and the other side is used to dry the other arm. (de Lissovoy $\mathbf{G}$ et al)

\section{Barrier techniques:}

Barrier techniques(using head cover, masks and cover gown) are helpful where the percentage of spread of infection is high.

- Head Cover

Before and during the operations, all facial and head hair should be joined properly and covered by using a head cover. Head covers should be single - use only and made of soft, impenetrable cloth like material. If one has long hair, the hair should be joined in a bun or even use a helmet, hood or head gears if it is not possible. (de Lissovoy G et al). 
- Masks

- Many infectious diseases can be spread through the air so wearing a mask is an efficient way to inhibit the spread of these diseases especially tuberculosis.

- The main purpose of wearing a mask is to inhibit the contamination by airborne infections from the members of the OR team or the surroundings to the patient's wounds and also protecting the OR staff from the splash of the patient's biological fluid.

- The masks are preferred to be single - use.

- The mask should be made of synthetic fibers, must be flat with three foldes to permit the inflate of the mask to cover the area from the nose to the chin, and should have polypropylene or polyester filters. (de Lissovoy $\mathbf{G}$ et al).

- Scrub suits and cover gowns.

The OR staff wear scrub suits instead of habitual clothing in the surgical operations to prevent the transference of any bacteria or viruses present on the clothing of the OR personnel to the patient or any other personnel. These should have a comfortable, simple design to decrease the chance of hiding contamination, easy to laundry, should be of low cost, easily replaceable if ruined (de Lissovoy $\mathbf{G}$ et al).

- Surgical gowns

These are additional layer of clothing to be worn over the scrub suits or cover gowns during a surgical operation to protect both the patient and the operating team from the transmission of microbes, blood or any other body fluids between them.

Steps of wearing gown: 
- With completely dry hands, hold the gown in a way that it is not subjected to microbes transfer.

- $\quad$ Slide arms into the sleeves through the armholes, keeping the gown up and apart from the body.

- Hold arms in a horizontal position.

- $\quad$ An assisting person should pull the gown on and tie the belts. (de Lissovoy G et al).

- $\quad$ Gloves

Wearing gloves is important to inhibit any exchange of microbes between the surgeon and the patient. So the surgeon will not acquire contamination from the patient's blood and the patient's cut will stay clean and not contaminated with the surgeon's normal bacterial flora. Many techniques of wearing gloves are applied.

- $\quad$ Steps to wear surgical gloves:-

- Hand washing must be carried out in a sterile conditions.

- Make sure the outer package is intact. Open the outer nonsterile packaging by removing it completely exposing the inner sterile wrap, but do not touch it.

- The inner sterile packaging is placed in a non humid area, without touching the outer surface. Open the package and fold it downwards so it would be easy to unfold the paper and keep it open.

- $\quad$ By using only two fingers(index and thumb) of one hand, grab the folded edge of the glove.

- Then the other hand is slided into the glove. 
- The second glove is picked by using the cuff of the other glove and sliding the fingers of the gloved hand into it.

- In one movement, slide the second glove on to the ungloved hand and be ware not to touch any other surface with the gloved hand. (National guide to infection control).

- $\quad$ Several approaches of disinfection of surgical instruments include:

- $\quad$ Cleaning any attached materials.

- Water distillation.

- $\quad$ Ultrasonic cleaning.

- Decontamination.

- $\quad$ Sterilization.

Processing of the clinical or surgical items is a two-step procedure.

\section{A-Cleaning any attached materials:-}

It is an important process, which is followed either by Decontamination or Sterilization.

- Cleaning may be done by hand or by washing machine and is normally done by the use of pure water, washing powder, and mechanical agents. Washing powder is important to dissolve proteins and fats that can be attached to the instruments and equipment during their use.

- Water can be purified by filtration, chemical disinfection or by ultraviolet radiation. (WHO, 2009). 


\section{Mechanical cleaning}

With the advanced washing machines, very little handling of the tools is done by the personnel so a limited chance of spreading infection is obtained.

- Washing machine: It use a gradual increase in the temperature of water, first there is a cold wash then a hot wash for 2 minutes at $71^{\circ} \mathrm{C}$ then a hot wash at $90^{\circ} \mathrm{C}$ for at least 10 seconds then the tools are dried at $75^{\circ} \mathrm{C}$ by hot air.

- Ultrasonicator: The ultrasonicator is a machine used to remove remnants effectively by the use of ultrasonic waves of power $0.44 \mathrm{~W} / \mathrm{cm}^{3}$.

- The solution mostly used to wash instruments is a pre-soak that contains enzymes as protease enzyme which removes protein attached to the instruments (Lippincott Williams \& Wilkins. 2001).

\section{Manual cleaning}

It is an effective way to clean equipments by using a toothbrush to thoroughly brush the item under water then they are dried.

Manual cleaning is necessary when:

- Cleaning by machines is not effective.

- Soft materials to be cleaned or objects with narrow lumen (Lippincott Williams \& Wilkins. 2001).

3. Soaking of instruments before cleaning:

In some cases, washing is not enough to remove all the remnant attached to the surgical tools so it is important to immerse these tools for some time before washing it. A deep container is filled with washing powder and 
water then the tools are immersed for 5 minutes, shaked vigorously, washed and left to dry.

\section{B. Disinfection and Sterilization:-}

- Disinfection or decontamination is done by many methods either thermal or chemical methods. The thermal disinfection process which is more easily manipulated, more trusted and non residual is a less toxic process. So it is preferred more than chemical disinfection process. The chemical disinfection is mainly used to disinfect the heat-sensitive objects. (Lippincott Williams \& Wilkins. 2001).

High level chemical disinfection (HLD):

a. Usually used for heat sensitive tools (e.g., endoscopes) where single use is not economic.

b. Disinfectants used for this objective are

- Glutaraldehyde: $2 \%$ for 20 min.

- Hydrogen peroxide: $6 \%-7.5 \%$ for $20-30 \mathrm{~min}$.

- Per acetic acid: $0.2-0.35 \%$ for $5 \mathrm{~min}$.

- Ortho-phthalaldehyde (OPA) for 5-12 min. (Lippincott Williams \& Wilkins. 2001).

- Sterilization

Sterilization is a process used to make the tools free of all types of microorganisms including spores. The main purpose of this process is to insure the safety of the patient. Sterilization is achieved by:

1. Steam sterilization (autoclaving):-

- This is the easiest and more reliable way of sterilizing tools that is wrapped or porous. 
- $\quad$ The steam autoclaves are suitable for outpatient practice and usually made to operate for 15 minutes at $250{ }^{\circ} \mathrm{F}\left(121^{\circ} \mathrm{C}\right)$ under 15 Psi

- For quick decontamination needed occasionally in the OR it can be operated for 3 minutes at $270^{\circ} \mathrm{F}\left(134^{\circ} \mathrm{C}\right)$ under 30 Psi. This is known as "flash sterilization".

- The mix of elevated temperature and humidity gives the best efficacy against almost all forms of microbes.

- Types of autoclaves are divided according to their design (vertical or horizontal) or their functioning (gravity displacement or vacuum).

- There are Autoclaves known to be of Type "N" and Type "B." according to the evacuation of air during sterilization process. Type "N" autoclaves, the air is still present during sterilization and it is used for solid objects.

- Type "B" autoclaves evacuate air from the sterilization chamber by the use of vacuum pump bagged and void objects are sterilized by this type of autoclaves and saved to be used some other time.

- Importance of bagging the instruments for sterilization.

- The bagging or wrapping of the instruments prior to sterilization process would reduce the percentage of transference of microbes to the tools after sterilization is finished. Double wrapping is preferred (Lippincott Williams \& Wilkins. 2001).

\section{Results:-}

- Inhibiting and managing infection is the most important factor in providing better health care that guarantee the safety of the patient and the health care personnel. SSIs are a result of microbial contamination in the sterile ORs. This contamination maybe from the air, one of the working 
personnel present at the time of operation, bad sterilization of instruments or even from the patient himself. Appropriate construction of OR, proper microbial management, appropriate sterilization and wearing surgical condoms are of the principles of inhibiting infection in OR.

\section{Discussion: -}

\section{Operating Room (OR)}

- The OR is a provision in the hospital where surgical interventions or operations are performed in a highly aseptic conditions. Since the OR must maintain highly aseptic conditions, it is essential for every health care worker to fully understand the rules, regulations, and professional guidelines that must be applied in the OR to avoid infection connected with Healthcare (HCAIs). Reliable infection inhibition and management is the crucial element to decrease the percentage of permanent disabilities or even death resulted from SSIs.

- The Following requirements should be fulfilled in ORs:

- Good illumination.

- Good aeration system.

- $\quad$ Correct and sufficient machinery needed during operation.

- Good supervision of the patient's condition and vital signs through the surgical operation.

- $\quad$ Life saving drugs and machines should be available.

- In order to maintain the maximum level of asepsis, it is recommended to build the surgical ward in a separate building away from the other wards.

- The Location of the Operating space: The operating space should be positioned so that both sufficient natural light and airflow are available. In 
order to achieve that the operating space should be away from the crowdedness of the hospital. (de Lissovoy $\mathbf{G}$ et al).

- Factors that may increase the spread of HCAIs during hospitalization:

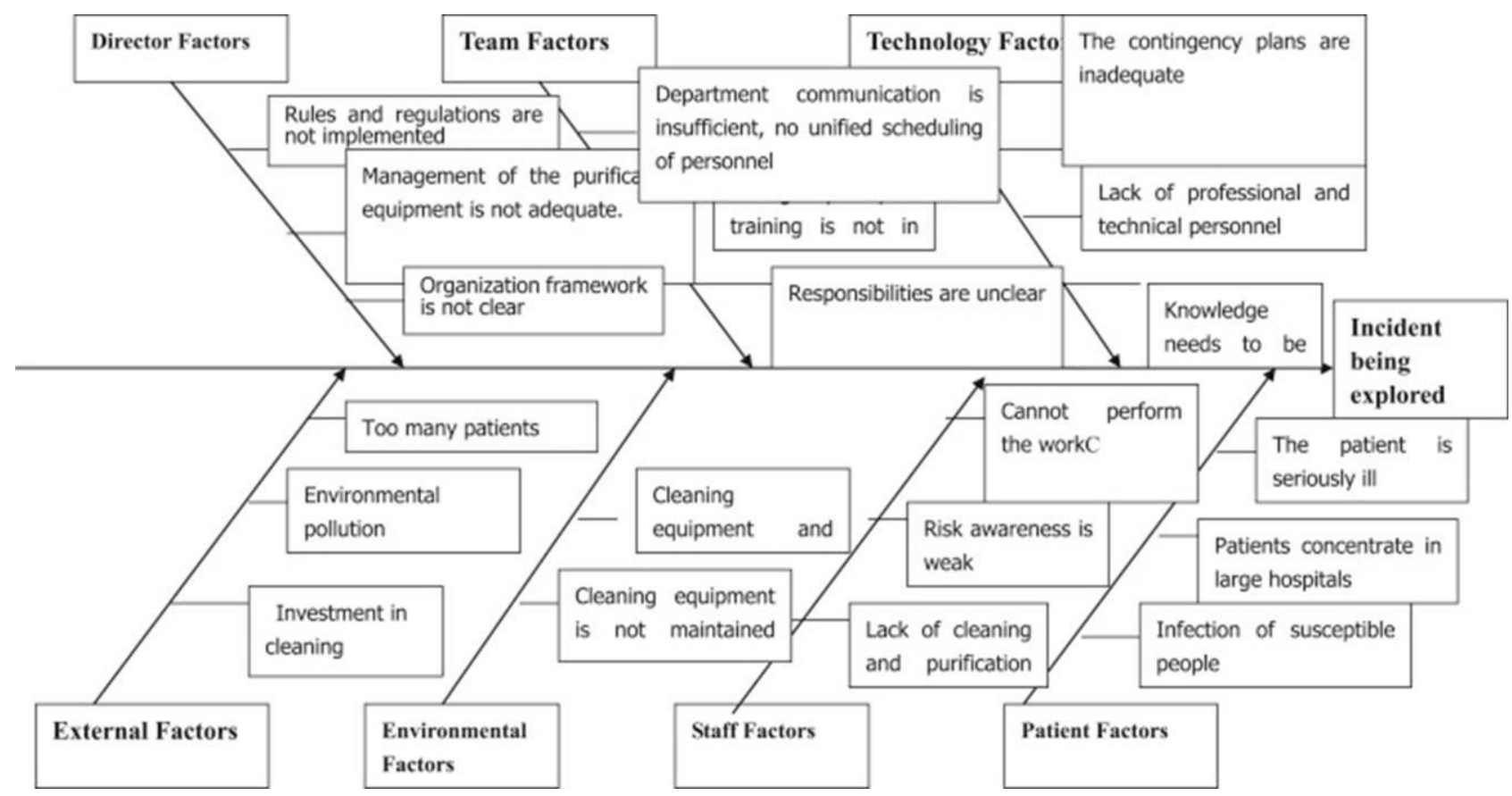

Figure 1: Factors that may increase HCAls

- According to the international journal of nursing sciences many system factors may increase SSIs leading to adverse events(fig.1)

Some factors are related to the working personnel such as the director factors, team factors, staff factors and patient factors. others are related to the technology or even external factors.

\section{- Anaesthetist factors (staff factor).}

- $\quad$ Colonization with microbiome (Biddle, 2009; Biddle and Shah, 2012).

- Inappropriate hand sanitation before, during and in-between cases.

(Loftus et al., 2008; Loftus et al., 2011). 
- No proper attention is paid not to touch any object that may be contaminated then transfer this infection to the patient (Boyce et al., 1997).

- Wearing jewelry or artificial nails.

- Washing the surgical scrubs at home.

- Improper movement around the patient's bed, inappropriate scene of actions to other OR staff (Biddle, 2009).

- Handling the patient without gloves (eg, giving I.V. starting anesthesia or suctioning).

- Increased the work load (too many cases to handle) and the quick response needed to any change in the patient's condition.

- Improper disinfection of monitoring machines between operations.

- No administration of antibiotics prior to the surgical operation or redosing after in the right intervals (Bratzler et al., 2013).

- Gender of the person: women have elevated level of bacterial flora and men are not keen to hand sanitation.

- $\quad$ Personnel are not keen to sustain solid aspectic conditions during long surgical operations.

- $\quad$ Reusage of tools that may have been infected (eg, using tools that may have come in contact with a non-sterile surface).

\section{- $\quad$ Patient factors}

- Colonization with microbiome (Biddle, 2009; Roy et al., 2011).

- Being infected with resistant bacterial strains (eg,MRSA, resistant enterococci, vancomycin).(Boyce et al., 1997).

- Infectious active diseases. 
- hindering of the immune system response due to the administration of general anesthesia.(Biddle, 2009).

- Hypothermia( decrease of the patient body temperature(Meiling et al., 2001).

\section{- Environment factors}

- Increased entry and exit of the OR during procedures (Lynch et al., 2009).

- Improper sterile techniques.

- Inadequate airflow /quality (Thiele et al., 2008).

- Design of the OR that facilitates spread of pathogens (Thiele et al., 2008).

\section{Conclusion:}

1. Construction of a surgical team and keeping a polished operating environment is wanted due to a number of peri-operative risk factors that take part in the evolution of SSIs.

2. Not much has changed over the years regarding the surgical habits of scrubbing, gloving, and gowning due to insufficient scientific data or due to behavioral reasons. Many of these habits are still practiced today to protect the surgical team rather than prevent SSIs.

3. When placing an implant in a clean surgical operation, care and attention are highly required to prevent SSIs which may happen due to contamination by surgical team members.

4. Wearing proper surgical attire, keeping OR doors closed, and traffic to a minimum are simple measures that decrease airborne contamination.

5. Every member of the surgical team has to apply the main principles of antisepsis in the OR.

6. Every OR department should have a strategy of developing its own infection control policy. 
7. Well authorized methods as (e.g. increased oxygen, glucose control, normothermia) avert SSIs and may decrease disease and death rates linked with SSIs and prices of healthcare.

\section{- Recommendations:-}

1. An infection control committee is to be formed which consists of a clinical infection control resident and a number of assisting nurses that differ according to the bed capacity of the hospital.

2. Create, apply and follow up an annual strategy to ensure medical safety measures.

3. Continuous learning plans are to be made for both the medical staff and the infection control team.

4. It is preferable to shower the patient with an antiseptic sol. such as povidone-iodine $7.5 \%$ or chlorhexidine in an appropriate concentration twice (the night before the surgery and at the morning).

5. giving antimicrobial prophylaxis half an hour- 2 hours before surgery(tab.1)

6. The hair is removed from the surgical site by an electric machine with a sterile head, and only the hair in the cut area is removed immediately before the surgery. No razor or scalpel is used to shave the hair.

7. Only the necessary staff members should be in the OR during a procedure.

8. Keep doors closed or a minimum entry to minimize air currents.

9. Commitment to disinfect hands, wear appropriate personal condomes is a must. 


\begin{tabular}{|lll|}
\hline $\begin{array}{l}\text { Table } 1 \\
\text { Guidelines for antimicrobial prophylaxis for surgery }\end{array}$ \\
\begin{tabular}{lll} 
Antimicrobial Agent & Recommended Dose (IV) & Redosing Interval \\
\hline Cefazolin & $2 \mathrm{~g}(3 \mathrm{~g}$ if pt wt $>120 \mathrm{~kg}) 30 \mathrm{mg} / \mathrm{kg}$ (pediatric) & $\mathrm{q} 3-4 \mathrm{~h}$ \\
\hline Cefotetan & $2 \mathrm{~g}$ & $\mathrm{q} 6 \mathrm{~h}$ \\
\hline Cefoxitin & $2 \mathrm{~g}$ & $\mathrm{q} 2 \mathrm{~h}$ \\
\hline Ciprofloxacin & $400 \mathrm{mg}$ & N/A \\
\hline Metronidazole & $500 \mathrm{mg}$ & N/A \\
\hline Vancomycin & $1 \mathrm{~g}(15 \mathrm{mg} / \mathrm{kg})$ & N/A \\
\hline Gentamicin & $80 \mathrm{mg}(5 \mathrm{mg} / \mathrm{kg})$ & N/A \\
\hline
\end{tabular}
\end{tabular}

Abbreviations: IV, intravenous; N/A, not applicable; pt, patient; wt, weight.

Data from Bratzler DW, Dellinger EP, Olsen KM, et al. Clinical practice guidelines for antimicrobial prophylaxis in surgery. Am J Health Syst Pharm 2013;70:195-283; and Anderson DJ, Podgorny K, Berrios-Torres S, et al. Strategies to prevent surgical site infections in acute care hospitals: 2014 update. Infect Control Hosp Epidemiol 2014;35(6):605-27.

10. It is preferable to use a laryngoscope with single blade.

11. Preparing the patient's skin: usage of a suitable antiseptic in circles, beginning from the center outwards, leaving it to dry completely.

12. The sanitized site must be larger than the cut enough to allow the cutting to be expanded, new cut to be made, or the instillation of drains if needed.

13. Suitable and efficient waste disposal is a must.

14. During pandemics especial care should be taken to insure the safety of medical staff and the patient (fig.2) 


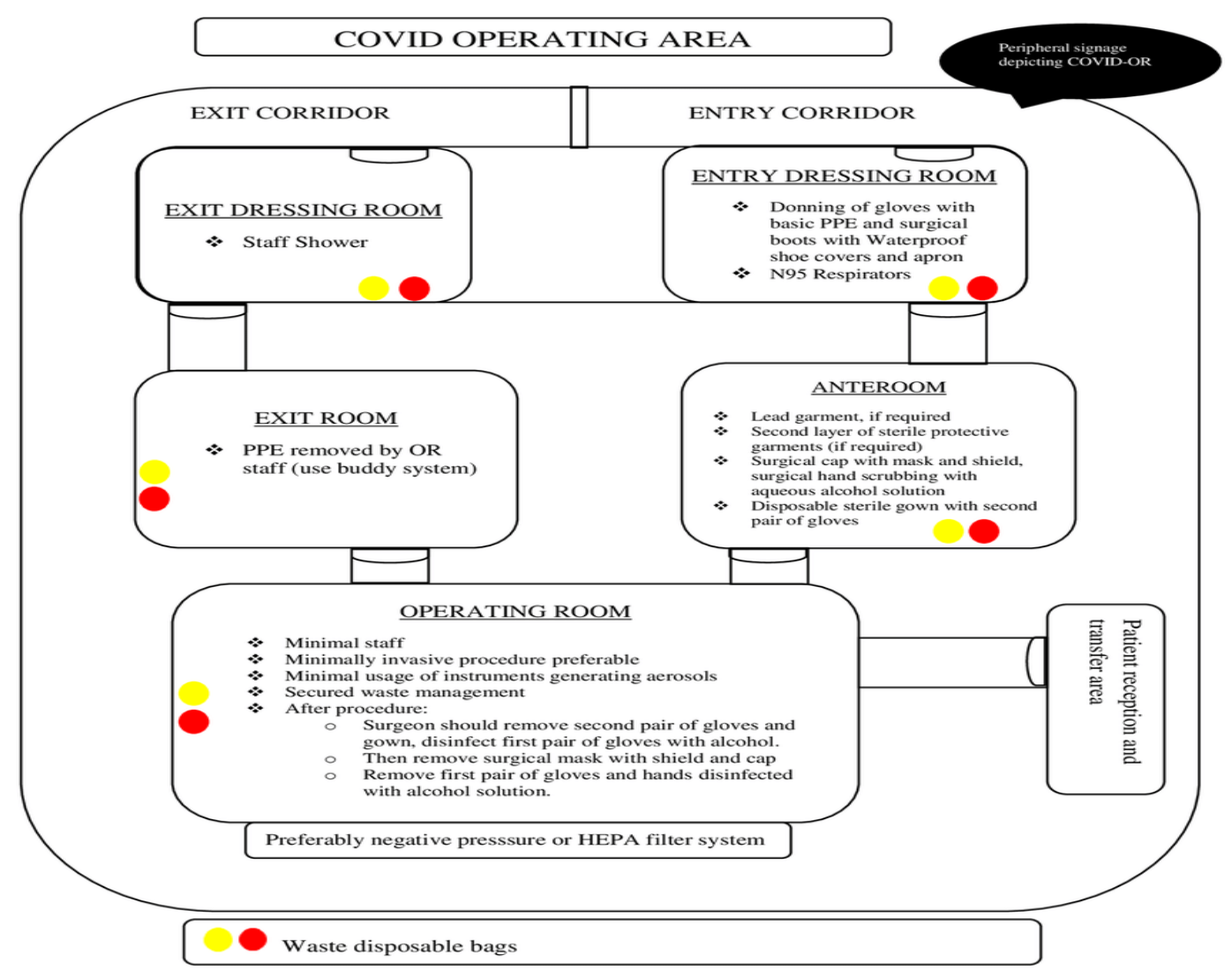

Figure 2: Figure 2: Diagram detailing the ideal operation theater set up during COVID- 19 pandemic(www.researchgate.net).

\section{Summary:-}

Good infection prohibition and management is the key to guarantee the safety of the patient submited to any surgical operation in the operating room. $20 \%$ of the total hospital-acquired infections are acquired in the surgical site(SSIs)(de Lissovoy $\mathbf{G}$ et al). These infections may cause permanent disability, death and highly increase healthcare expensies Preparation of the surgical team and maintaining a sterile operating environment are the key factors to reduce many of peri-operative risk factors which can lead to the growth of SSIs.

It is recommended to create, apply and follow up an annual infection control strategy to ensure medical safety measures.Also strict attention to hand hygiene and a good preparation of the patient is to be considered. 


\section{References:-}

- Lo Giudice, D., Trimarchi, G., La Fauci, V., Squeri, R., \& Calimeri, S. (2019). Hospital infection control and behaviour of operating room staff. Central European Journal of Public Health, 27(4), 292-295.

- Fashafsheh, I., Ayed, A., Eqtait, F., \& Harazneh,

- L. (2015). Knowledge and Practice of Nursing Staff towards Infection Control Measures in the Palestinian Hospitals. Journal of Education and Practice, 6(4), 79-90.

- WHO. (2009). WHO Guidelines on Hand Hygiene in Health Care. Geneva: WHO.

- A. G. (2016). Knowledge and practices of infection control among healthcare workers in a Tertiary Referral Center in NorthWestern Nigeria. Annals of African medicine, 15(1), 34

- Gammon, J., Morgan_Samuel, H., \& Gould, D. (2008). A review of the evidence for suboptimal compliance of healthcare practitioners to standard/universal infection control precautions. Journal of clinical nursing, 17(2), 157-167.

- Brady, R. R. W., McDermott, C., Gibb, A. P., \& PatersonBrown, S. (2008). Fact or infection: do surgical trainees know enough about infection control?. The Annals of The Royal College of Surgeons of England, 90(8), 647-650.

- Zafar, A., Habib, F., Hadwani, R., Ejaz, M., Khowaja, K., Khowaja, R., \& Irfan, S. (2009). Impact of infection control activities on the rate of needle stick injuries at a tertiary care hospital of Pakistan over a period of six years: an observational study. BMC infectious diseases, 9(1), 78. 
- Healthcare-associated infections (HAIs). Centers for Disease Control and Prevention Web site. Available at: http://www.cdc.gov/HAI/surveillance/index. html. Accessed September 2, 2014.

- Biddle C. Semmelweis revisited: hand hygiene and nosocomial disease transmis- sion in the anesthesia workstation. AANA J 2009;77(3):229-37

- Biddle C. Semmelweis revisited: hand hygiene and nosocomial disease transmis- sion in the anesthesia workstation. AANA J 2009;77(3):229-37.

- Biddle, C. (2009). Semmelweis revisited: hand hygiene and nosocomial disease transmission in the anesthesia workstation. AANA journal 77.

- Biddle, C., and Shah, J. (2012). Quantification of anesthesia providers' hand hygiene in a busy metropolitan operating room: what would Semmelweis think? American journal of infection control 40, 756-759.

- Boyce, J.M., Potter-Bynoe, G., Chenevert, C., and King, T. (1997). Environmental contamination due to methicillin-resistant Staphylococcus aureus possible infection control implications. Infection Control \& Hospital Epidemiology 18, 622-627.

- Bratzler, D.W., Dellinger, E.P., Olsen, K.M., Perl, T.M., Auwaerter, P.G., Bolon, M.K., Fish, D.N., Napolitano, L.M., Sawyer, R.G., and Slain, D. (2013). Clinical practice guidelines for antimicrobial prophylaxis in surgery. Surgical infections 14 , 73-156.

- Loftus, R.W., Koff, M.D., Burchman, C.C., Schwartzman, J.D., Thorum, V., Read, M.E., Wood, T.A., and Beach, M.L. (2008). Transmission of pathogenic bacterial organisms in the 
anesthesia work area. The Journal of the American Society of Anesthesiologists 109, 399-407.

- Loftus, R.W., Muffly, M.K., Brown, J.R., Beach, M.L., Koff, M.D., Corwin, H.L., Surgenor, S.D., Kirkland, K.B., and Yeager, M.P. (2011). Hand contamination of anesthesia providers is an important risk factor for intraoperative bacterial transmission. Anesthesia \& Analgesia 112, 98-105.

- Lynch, R.J., Englesbe, M.J., Sturm, L., Bitar, A., Budhiraj, K., Kolla, S., Polyachenko, Y., Duck, M.G., and Campbell Jr, D.A. (2009). Measurement of foot traffic in the operating room: implications for infection control. American Journal of Medical Quality 24, 45-52.

- Meiling, A., Ali, B., Scott, E., and Leaper, D. (2001). Effects of preoperative warming on the incidence of wound infection after clean surgery: a randomised controlled trial (published correction appears in Lancet 2002; 359: 896). Lancet 358, 876-880.

- Roy, R.C., Brull, S.J., and Eichhorn, J.H. (2011). Surgical site infections and the anesthesia professionals' microbiome: we've all been slimed! Now what are we going to do about it? Anesthesia \& Analgesia 112, 4-7.

- Thiele, R.H., Huffmyer, J.L., and Nemergut, E.C. (2008). The "six sigma approach" to the operating room environment and infection. Best practice \& research Clinical anesthesiology 22, 537-552.

- https://www.researchgate.net/figure/A-line-diagram-detailingthe-ideal-operation-theatre-set-up-during-COVIDpandemic_fig1_341522745.

- International journal of nursing sciences, vol.2, issue 4, December 2015,pg.348-354.: 
- https://doi.org/10.7861/clin

medicine.14-5-

468ClinMedOctober 2014.

- Ray MC modern approaches to preventing surgical site infections.

- The National Guide to infection control 2016, vol.2, issue 3, pg.77-88.

- https://www.ncbi.nlm.nih.gov/pmc/articles/PMC7882240/

- Edmiston CE, Lee CJ, Krepel CJ, Spencer M, Leaper D, Brown KR, Lewis BD, Rossi PJ, Malinowski MJ, Seabrook GR. Evidence for a standardized preadmission showering regimen to achieve maximal antiseptic skin surface concentrations of chlorhexidine gluconate, 4\%, in surgical patients. JAMA Surg. 2015;150(11):10271033. doi: 10.1001/jamasurg.2015.2210. [PubMed] [CrossRef] [Google Scholar]

- Block SS. Definition of terms. Disinfection, sterilization, and preservation. Philadelphia: Lippincott Williams \& Wilkins.2001:1928.

- de Lissovoy G, Fraeman K, Hutchins V, Murphy D, Song D, Vaughn BB. Surgical site infection: incidence and impact on hospital utilization and treatment costs. Am J Infect Control. 2009;37(5):387397. doi: 10.1016/j.ajic.2008.12.010. [PubMed] [CrossRef] [Google Scholar] 